\title{
ESTUDO DA EFICÁCIA DE UM NOVO PRODUTO À BASE DE ÁLCOOL GEL UTILIZADO NA ANTI-SEPSIA EM UM SERVIÇO DE NEFROLOGIA*
}

\author{
STUDY OF THE EFFECTIVENESS OF A NEW PRODUCT TO THE ALCOHOL GEL \\ BASE UTILIZED AS AN ANTISEPTIC IN A NEPHROLOGY SERVICE
}

Geni Burg${ }^{1}$, Odete Portela ${ }^{1}$, Gustavo Luiz Paraginski², Viviane de Souza ${ }^{3}$,

Djalma Dias da Silveira' ${ }^{4}$, Rosmari Hörner ${ }^{5}$

\begin{abstract}
${ }^{1}$ Mestrandas do Programa de Pós-Graduação em Engenharia de Produção. Centro de Ciências Naturais e Exatas-UFSM. ${ }^{2}$ Mestrando do Programa de Pós-Graduação em Ciências Farmacêuticas. Centro de Ciências da Saúde - UFSM. ${ }^{3}$ Farmacêutica-bioquímica. Laboratório Labdiagnósticos. ${ }^{4}$ Docente. Departamento de Engenharia Química. Centro de Tecnologia - UFSM. ${ }^{5}$ Docente. Departamento de Análises Clínicas e Toxicológicas. Centro de Ciências da Saúde-UFSM

CorRespondência: Rosmari Hörner. Departamento de Análises Clínicas e Toxicológicas - Salas 1201 e 1205 - Prédio 26 - Centro de Ciências da Saúde - Universidade Federal de Santa Maria.

Avenida Roraima no 1000 - Cidade Universitária - Bairro Camobi. CEP: 97105-900 - Santa Maria RS

Telefone: (55)-3220-8464. e-mail: rosmari@smail.ufsm.br
\end{abstract}

Burg G, Portela O, Paraginski GL, Souza V, Silveira DD, Hörner R. Estudo da eficácia de um novo produto à base de álcool gel utilizado na anti-sepsia em um serviço de nefrologia. Medicina (Ribeirão Preto) 2007; 40 (2): $236-42$.

Resumo: A atenção à saúde é permanentemente desafiada pelas infecções relacionadas aos procedimentos assistenciais, que resultam no aumento da morbidade, mortalidade e custos operacionais. O álcool etílico possui propriedades antimicrobianas reconhecidas, capazes de eliminar os microrganismos mais freqüentemente envolvidos nas infecções em serviços de saúde. A maior desvantagem do álcool para a anti-sepsia da pele é seu efeito ressecante. Este estudo foi realizado na Clínica Renal de Santa Maria, RS, com o objetivo de avaliar a eficácia antiséptica de um novo produto à base de álcool gel (Biogel囚), na tentativa de eliminar a necessidade da lavagem com água e sabão do braço com a Fístula Artério Venosa (FAV), dos pacientes submetidos à hemodiálise. A metodologia utilizada foi um estudo experimental do tipo "Ensaio Clínico Randomizado" realizado com onze pacientes ambulatoriais submetidos à hemodiálise nos meses de janeiro a fevereiro de 2005. Foi efetuada cultura da pele anterior e posterior ao procedimento da anti-sepsia, utilizando o álcool $70 \%$ e o produto Biogel囚, e avaliação da atividade antibacteriana do Biogel $\circledast$, frente à bactérias gram-positivas e gram-negativas correspondentes à cepas nosocomiais isoladas de pacientes atendidos no Hospital Universitário de Santa Maria (HUSM). Os resultados mostraram igual desempenho dos dois métodos de anti-sepsia, apresentando uma atividade anti-séptica de $72,7 \%$, e conferindo também atividade bactericida ao Biogelß, frente às cepas testadas.

Descritores: Álcoois. Desinfecção. Anti-Sepsia. Hemodiálise. Infecção Hospitalar.

\footnotetext{
* Trabalho desenvolvido na Clínica Renal de Santa Maria e no Laboratório de Bacteriologia do Departamento de Análises Clínicas e Toxicológicas (DACT), Centro de Ciências da Saúde (CCS), com a orientação dos Programas de Pós-Graduação em Engenharia de Produção e Ciências Farmacêuticas. Universidade Federal de Santa Maria (UFSM).
} 


\section{1- INTRODUÇÃO}

As infecções nosocomiais constituem na atualidade um dos maiores problemas de saúde pública, gerando um aumento significativo nos custos assistenciais ${ }^{1}$. Por mais de um século, a higiene da pele, particularmente das mãos, tem sido aceita como o mecanismo primário para controlar a disseminação dos agentes infecciosos. A relação entre mãos contaminadas e transmissão de doenças infecciosas constitui um dos fenômenos melhor documentados na ciência clínica ${ }^{2}$. A lavagem das mãos é a principal medida na prevenção das infecções hospitalares ${ }^{3,4}$, constituindo um dos componentes básicos de qualquer programa de controle de infecção, e é freqüentemente considerada sinônimo de higienização das mãos ${ }^{5}$. A desinfecção de ambientes e a anti-sepsia das mãos com soluções alcoólicas, sem a necessidade de aplicação prévia de água e sabão, é comumente utilizada em vários países da Europa, há muitos anos, assumindo importância e adesão cada vez maior ${ }^{1,6}$. Os Estados Unidos, apesar de não possuírem tradição na utilização do álcool nos serviços de assistência à saúde, vêm, paulatinamente, se rendendo aos estudos que comprovam sua eficiência. No Brasil, o álcool, há anos, é utilizado como desinfetante, porém, a idéia de substituir a lavagem das mãos pela anti-sepsia com álcool, ainda é pouco aceita. O conhecimento insuficiente em relação aos processos de higienização, que compreendem a lavagem das mãos com água e sabão comum ou com sabão anti-séptico e a fricção com soluções alcoólicas, conduz a uma situação bastante heterogênea, neste país continental. Assim, alguns serviços de saúde e hospitais, já incorporaram o conhecimento de que higienizar as mãos é muito mais que simplesmente lavá-las com água e sabão. A lavagem das mãos com água e sabão comum promove a remoção mecânica de sujidades presentes na pele. A lavagem das mãos com sabão anti-séptico, além de promover arrastamento de sujidades e de microrganismos, acentua a redução na carga microbiana por sua ação sobre a microbiota residente. Já a higienização das mãos sem a água, obtida pela fricção de soluções alcoólicas na pele, possui eficácia na redução da carga microbiana, mas não promove arrastamento de sujidade ${ }^{6}$.

A pele apresenta uma população de microrganismos que constituem a microbiota residente (normal), os quais se multiplicam e persistem sobre ela, e a outra que constitui a microbiota transitória, constituída por microrganismos depositados sobre a pele, sem que ocorra a colonização. Os microrganismos residentes podem ser isolados persistentemente da pele da maioria das pessoas, sendo principalmente representados por microrganismos de baixa patogenicidade, ou oportunistas, sendo que as infecções ocasionadas por estas bactérias, usualmente afetam as pessoas que se encontram com baixa imunidade. Típicos exemplos dessa microbiota são representados pelos gêneros Propionibacterium spp, Corynebacterium spp, Staphylococcus coagulase-negativo (SCN) e ocasionalmente bacilos gram-negativos não fermentadores (BGN-NF) como Acinetobacter spp. A microbiota transitória é representada por microrganismos isolados da pele, mas não demonstram estarem presentes na maioria das pessoas. Estas bactérias são responsáveis por surtos de infecções relacionadas com as mãos contaminadas dos profissionais da saúde. A microbiota transitória tem origem no contato com os pacientes ou o ambiente, se constituindo típicos exemplos, Escherichia coli, Pseudomonas aeruginosa, Serratia spp, Proteus spp, Klebsiella spp, Acinetobacter spp, Staphylococcus aureus, entre outros ${ }^{5,7,8}$. Os agentes antisépticos são utilizados para reduzir o número de microrganismos existentes nas camadas superficiais (microbiota transitória) e profundas (microbiota residente) da pele e das mucosas ${ }^{1,4,5}$.

Os compostos anti-sépticos são selecionados em relação a sua segurança e eficiência. Embora os álcoois tendem a ressecar a superfície da pele devido à remoção dos lipídios, eles não são tóxicos e têm uma excelente atividade contra todos os grupos de microrganismos, exceto contra os esporos ${ }^{7}$. O mecanismo de ação dos álcoois ainda não foi totalmente elucidado, porém, a desnaturação das proteínas é a explicação mais plausível. $\mathrm{Na}$ ausência da água, as proteínas não são desnaturadas tão rapidamente quanto na presença dela, razão pela qual, o etanol absoluto, um agente desidratante, é menos ativo do que soluções aquo$\operatorname{sas}^{1,9,10,11 .}$.

A prevalência de microrganismos resistentes aos antimicrobianos nos serviços de saúde, incluindo os serviços de diálise, nosocomial ou ambulatorial, tem aumentado dramaticamente na última década ${ }^{12 / 15}$. Os numerosos contatos entre os membros do serviço de hemodiálise e os pacientes constituem uma oportunidade para a transmissão destes patógenos, de paciente a paciente ${ }^{16}$. Medidas para o controle de infecção recomendada para todos os pacientes da hemodiálise são direcionadas para prevenir a transmissão para a maioria dos pacientes infectados ou colonizados com 
bactérias patogênicas, incluindo cepas resistentes aos antimicrobianos ${ }^{16}$. Porém, algumas precauções adicionais para estes pacientes de hemodiálise têm sido sugeridas, por se tratarem de pacientes terminais, imunodeprimidos, e com risco aumentado para transmissão de microrganismos patogênicos ${ }^{16}$.

Foi percebido na rotina dos pacientes que realizam hemodiálise a resistência na lavagem do braço com água e sabão na região da FAV, anteriormente às punções. Os profissionais que prestam assistência a esta população necessitam periodicamente conscientizá-los da necessidade desta lavagem anterior à punção da FAV, para evitar problemas de infecção, assim como, os pacientes com limitações físicas, necessitam de auxílio da equipe de profissionais, para realizar o procedimento de lavagem do braço da FAV.

Este estudo foi realizado na Clínica Renal de Santa Maria, RS, com o objetivo de avaliar a eficácia anti-séptica de um novo produto à base de álcool gel (Biogel®), na tentativa de eliminar a necessidade da lavagem com água e sabão do braço com a Fístula Artério Venosa (FAV), dos pacientes submetidos à hemodiálise. Também determinou-se sua atividade antibacteriana, conforme apresentado adiante.

\section{2- MATERIAIS E MÉTODOS}

A metodologia utilizada neste estudo experimental foi do tipo "Ensaio Clínico Randomizado". Este estudo foi realizado na Clínica Renal de Santa Maria$\mathrm{RS}$, com pacientes portadores de insuficiência renal crônica, submetidos à hemodiálise. A referida Clínica atua na área da Nefrologia há 20 anos, atendendo 260 pacientes em programa regular de hemodiálise. $\mathrm{Na}$ metodologia utilizada nesta modalidade de investigação os participantes são colocados aleatoriamente para formar o grupo de estudo e o controle ${ }^{17}$.

A pesquisa foi desenvolvida em duas etapas, sendo que a primeira etapa constituiu basicamente a mais importante, e representando a segunda, um acompanhamento do novo tipo de procedimento adotado, isto é, a higienização e anti-sepsia do braço com a FAV com o álcool gel, produto Biogel®. Assim, na primeira etapa, foi efetuado o estudo da eficácia do álcool $70 \%$ e do Biogel ${ }^{\circledR}$, com a avaliação da atividade antimicrobiana do Biogel $\AA$, realizada nos meses de janeiro a fevereiro de 2005, com 11 pacientes ambulatoriais submetidos à hemodiálise na referida clínica, os quais concordaram em participar assinando o Termo de Consentimento Livre e Esclarecido, previamen- te aprovado pelo Comitê de Ética da Clínica e da Universidade Federal de Santa Maria (UFSM-RS). Esta amostragem de 11 pacientes para o grupo teste e 3 para o grupo controle, foi selecionada, motivada pelo grande número de tipos diferentes de colônias desenvolvidas nas placas de cultura, e que necessitam posterior identificação fenotípica, tornando laboriosa e cara a pesquisa.

A segunda etapa da pesquisa foi efetuada no período de entre março a julho de 2005 , com o objetivo de avaliar os efeitos adversos da anti-sepsia com álcool 70\% e Biogel®, como prurido, irritação da pele, ressecamento e vermelhidão. Também se avaliou os índices de infecção, analisando os dados referentes aos episódios de bacteremia e pirogenia neste período. Nesta etapa um total de 202 pacientes submetidos ao tratamento da hemodiálise foi dividido em dois grupos, sendo o grupo $\mathrm{A}$, correspondente à anti-sepsia com álcool $70 \%$ e o grupo $\mathrm{B}$, à anti-sepsia com o Biogel®.

PRIMEIRA ETAPA: Neste estudo de avaliação da eficácia de dois anti-sépticos, foram utilizados o álcool 70\% (Aproquin Comércio de Produtos Químicos), e o Biogel@ (BIOBUS), produto especialmente formulado para efetuar a assepsia das mãos, sem a necessidade da utilização da água ou de qualquer outro tipo de substância líquida, proporcionando à pele, conforto e maciez, devido à sua composição química. Sua apresentação é na forma de gel, com pH neutro, contendo na sua constituição química tricloro hidroxidifenileter, dietanolamina de óleo de côco, álcool etílico a $70 \%$ e água bidestilada. Nas recomendações de uso do fabricante consta a aplicação de uma pequena quantidade, em torno de $2 \mathrm{ml}$ sob uma gaze, friccionando posteriormente o local da FAV por 30 segundos, após aguardando por mais um minuto.

Inicialmente coletou-se "swabs" da superfície cutânea do antebraço dos pacientes, no local da FAV, correspondendo a uma superfície de pele padronizada de $5 \mathrm{~cm}^{2}$, para a realização das culturas. O procedimento técnico de coleta foi realizado, seguindo os Procedimentos Operacionais Padrões (POP) idealizados no projeto de execução. As coletas eram efetuadas em dois dias distintos das sessões de hemodiálise, com intervalo de um dia.

No primeiro dia, correspondendo ao primeiro passo, foram coletados "swabs" da superfície cutânea do paciente em sua sessão de hemodiálise, anterior à realização de qualquer método de anti-sepsia, com o objetivo de determinar a microbiota bacteriana da pele. 
Posteriormente, o paciente era instruído, a lavar com água e sabão líquido a região da FAV (procedimento obrigatório constante do Manual de Procedimentos Operacionais Padrões - POP , da equipe de enfermagem), consecutivamente secando com papel toalha. A seguir era efetuada a anti-sepsia da pele utilizando o anti-séptico álcool a 70\%, aguardando cerca de um minuto para proceder à coleta de novo "swab" da mesma região coletada anteriormente a este procedimento.

No segundo dia, os pacientes não realizavam a sessão de hemodiálise, devido a rotina neste serviço de nefrologia.

No terceiro dia, procedia-se, da mesma forma relatada no primeiro dia, efetuando a coleta anterior à anti-sepsia, já descrita acima (o primeiro passo). Posteriormente, efetuava-se a anti-sepsia da pele na região da FAV, utilizando $2 \mathrm{~mL}$ do anti-séptico Biogel ${ }^{\circledR}$ sob uma gaze estéril, friccionando por 30 segundos pela mesma equipe, e aguardando um minuto para efetuar a coleta com "swab", da já citada região onde se encontra a FAV.

As amostras, conforme estavam sendo coletadas em "swabs" estéreis, eram imediatamente acondicionadas em tubos de ensaio contendo 2 mililitros do meio Brain Heart Infusion (BHI), e encaminhadas, ao Laboratório de Bacteriologia da Universidade Federal de Santa Maria (UFSM), para processamento bacteriológico. A semeadura foi efetuada por meio de metodologia semiquantitativa, em placas médias (100 mm de diâmetro), utilizando o meio enriquecido de ágar sangue de carneiro (5\%). Posteriormente à semeadu$\mathrm{ra}$, as placas foram incubadas em estufa bacteriológica, $35^{\circ} \mathrm{C} \pm 2^{\circ} \mathrm{C}, 24-48$ horas. Foram consideradas culturas positivas as que apresentaram desenvolvimento de microrganismos até 48 horas de incubação. Das culturas positivas procedemos à identificação fenotípica convencional ${ }^{18,19}$ das diferentes colônias que apresentaram maior desenvolvimento (maior número de Unidades Formadoras de Colônias = UFC), as quais se constituíram basicamente da coloração de Gram, provas da catalase, coagulase livre, e outros testes bioquímicos, utilizados para a identificação do agente isolado. Paralelamente ao teste, foi constituído um grupo controle, composto de três pacientes submetidos à hemodiálise, procedendo-se da mesma maneira quanto às coletas e culturas da superfície cutânea, ou seja, anti-sepsia com água e sabão e demais procedimentos igualmente.
Também foi testada a atividade bactericida do anti-séptico Biogel®, utilizando cepas bacterianas isoladas de pacientes atendidos no Hospital Universitário de Santa Maria (HUSM), e identificadas por meio do sistema semiautomatizado (MicroScan -DADE Behring), representadas por $P$. aeruginosa, Enterobacter cloacae, Ralstonia pickettii, Acinetobacter baumannii, S. aureus, Staphylococcus saprophyticus e Bacillus cereus. Neste teste da atividade antimicrobiana do Biogel foram inoculados $50 \mu \mathrm{L}$ de inóculo padronizado (escala 0,5 McFarland) de cada um dos microrganismos acima citados, em tubos de ensaio contendo $2 \mathrm{~mL}$ de Biogel ${ }^{\circledR}$, e posteriormente incubados a $35^{\circ} \mathrm{C}$ por 24 horas. Após as 24 horas de incubação era efetuado o repique do Biogel ${ }^{\circledR}$ inoculado, no meio de MacConkey (seletivo para bacilos gram-negativos), e no meio de ágar sangue de carneiro, incubando-os posteriormente a $35^{\circ} \mathrm{C}$ por $24-48$ horas. Os meios nos quais não se evidenciaram colônias foram considerados negativos, conferindo atividade bactericida ao Biogel@. Nas placas com colônias visíveis, foram procedidas as identificações pela metodologia convencional, como relatada acima.

SEGUNDA ETAPA: De março a julho de 2005, após os resultados bacteriológicos da $1^{\mathrm{a}}$ etapa, foram analisados os efeitos adversos do uso rotineiro dos antisépticos como prurido, irritação e ressecamento da pele e os sinais e sintomas de infecção (como dor, calor, rubor, edema e exsudato) no local da FAV, bem como a presença de bacteremia (febre, calafrios e sinais de toxemia), logo após as punções, e durante a sessão de hemodiálise. Na presença de sinais e sintomas de infecção, foi estabelecido um protocolo de coleta de hemoculturas. Nesta etapa 202 pacientes foram estudados e foram divididos em dois grandes grupos, correspondendo o grupo A o dos pacientes cuja anti-sepsia fora efetuada com álcool $70 \%$ e o grupo B com a utilização do Biogel®. Os efeitos adversos e os sinais e sintomas de infecção, foram observados diariamente, durante os cinco meses de realização da pesquisa.

A procedência dos pacientes que participaram desta etapa da pesquisa, aproximadamente $50 \%$, pertenciam à cidade de Santa Maria, e os outros, às cidades de Agudo, Caçapava do Sul, Cacequi, Dona Francisca, Julho de Castilhos, Faxinal do Soturno, Nova Palma, Paraíso do Sul, Quevedos, Restinga Seca, Santiago, São Sepé, São João do Polêsine, São Pedro do Sul e São Vicente. 


\section{3- RESULTADOS}

PRIMEIRA ETAPA: Os microrganismos identificados nas culturas da pele dos pacientes submetidos à hemodiálise na Clínica Renal de Santa Maria foram cocos gram-positivos, especificamente $S$. $a u$ reus e SCN. No grupo controle, obteve-se o isolamento de SCN.

A eficácia da anti-sepsia realizada com o álcool $70 \%$ e com o Biogel® foi a mesma, com um índice de $72,7 \%$ de culturas negativas, e $27,3 \%$ de culturas positivas, do total de amostras analisadas neste estudo. Nas culturas positivas foram isolados $\mathrm{SCN}$ no grupo A, isto é, após a anti-sepsia com álcool $70 \%$, e no grupo B, S. aureus e SCN, isto é, após a anti-sepsia com Biogel@.

$\mathrm{Na}$ análise da atividade antimicrobiana, o Biogel ${ }^{\circledR}$ foi capaz de matar as bactérias testadas, ou seja, apresentou atividade bactericida dentro 24 horas frente às bactérias $P$. aeruginosa, E. cloacae, $R$. pickettii, A. baumannii, S. aureus e S. saprophyticus, cepas isoladas de espécimes clínicos de pacientes internados no Hospital Universitário de Santa Maria (HUSM).

SEGUNDA ETAPA: Os pacientes estudados nesta etapa, ao que se refere às doenças virais, dos que faziam parte do grupo A (anti-sepsia com álcool $70 \%$ ) nenhum era portador de hepatite C, B ou SIDA, enquanto no grupo B (anti-sepsia com Biogel $\left.{ }^{\circledR}\right), 29 \%$ eram portadores do vírus da hepatite $\mathrm{C}$ e $6 \%$ da hepatite B. Isto pode ter influência nos resultados obtidos, pois sabe-se que os pacientes que não possuem hepatite C, B ou SIDA são mais resistentes a infecções bacterianas, ou seja, são mais imunocompetentes.

Em relação ao sexo, no grupo A (anti-sepsia com álcool 70\%), 63\% pertenciam ao sexo masculino, e $37 \%$ ao feminino, e no grupo B (anti-sepsia com Biogel ${ }^{\circledR}$ ), $51 \%$ ao sexo masculino e $49 \%$ ao feminino.

A faixa etária prevalente, com aproximadamente um quarto dos pacientes, nos dois grupos (A e B), foi a de 51 - 60 anos de idade.

Também é importante destacar que aproximadamente $35 \%$ dos pacientes dos dois grupos têm acima de 60 anos de idade, muitos com acuidade visual diminuída, dificuldade de deambular e de se movimentar, assim apresentando muita dificuldade na lavagem do braço da FAV antes da sessão de hemodiálise.

Com referência às patologias causais da insuficiência renal crônica, as fontes são variadas, como: diabete melitus, nefroesclerose hipertensiva, glome- rulopatias, pielonefrite, lupus eritematoso, uropatias, além das indeterminadas e outras das que foram citadas acima.

Com respeito à avaliação dos efeitos adversos, nenhum paciente apresentou sinais, em relação à ocorrência de bacteremias ou sinais e sintomas de infecção relacionados à via de acesso (FAV), dos dois grupos de pacientes estudados. Também não houve desenvolvimento de microrganismos na hemocultura, que estivesse relacionado à anti-sepsia do local da punção da FAV.

\section{4- DISCUSSÃO}

Existem três maneiras de se realizar a higiene das mãos no ambiente hospitalar e nos locais que se prestam serviços de atenção à saúde, como no serviço de hemodiálise, que são: a lavagem com água e sabonete (com ou sem anti-sépticos), aplicação de álcool gel e a aplicação de álcool na forma líquida ${ }^{20}$. A utilização dos álcoois na anti-sepsia e desinfecção representa uma prática freqüente nas instituições de saúde $^{21}$, existindo um consenso na literatura científica a respeito da concentração efetiva, que foi fixada em $70 \%$ em peso (entre $68 \%$ e $72 \%)^{1,10,11,21}$. Portanto, o álcool, nas concentrações apropriadas, representa um anti-séptico de baixo custo, extremamente rápido e eficaz para reduzir o número de microrganismos encontrados na pele. Nos últimos anos, algumas preparações comerciais foram efetuadas, associando o álcool etílico ou isopropílico com emolientes para minimizar o efeito do ressecamento da pele que é o álcool gel. Esta associação, segundo alguns autores, prolonga sua atividade bactericida, por retardamento de sua evaporação ${ }^{1,22}$. Os primeiros álcoois géis que surgiram no mercado tiveram seu uso limitado devido ao alto custo, o que não ocorre mais, uma vez que o preço do álcool $70 \%$ e o álcool gel se equivalem.

$\mathrm{SCN}$ e $S$. aureus, os microrganismos isolados na cultura da pele dos pacientes envolvidos em nosso estudo constituem as bactérias que fazem parte, respectivamente, da microbiota residente e da transitória da pele ${ }^{1,4,5}$.

Neste estudo obtivemos igual eficácia da antisepsia realizada com o álcool $70 \%$ e o Biogel®, com um índice de 72,7\% de redução para culturas negativas.

$\mathrm{Na}$ literatura, encontramos várias citações referentes à eficácia do álcool líquido $70 \%$ comparativamente ao álcool gel. Em determinado estudo, o álcool 
líquido foi comparado com o álcool gel, ambos friccionados com $3 \mathrm{~mL}$, a partir de mãos contaminadas artificialmente com E. coli: a redução deste bacilo gramnegativo foi significativamente maior quando da utilização do álcool líquido ${ }^{23}$ Em outro estudo comparativo, o álcool gel apresentou a mesma efetividade que o álcool líquido $70 \%$, o gluconato de clorohexidina $4 \%$ e o sabão líquido contendo $10 \%$ de iodopovidina (PVPI $10 \%$ ) na remoção de A. baumannii, S. aureus meticilina resistente (MRSA), E. coli, Enterococcus faecalis, $P$. aeruginosa e o fungo leveduriforme Candida albicans ${ }^{22}$. A publicação dos dados desta última citação, relatando a concordância ocorreu em 2004, e foram considerados pelos autores como sendo a primeira tentativa, no Brasil, em comparar o efeito do álcool gel e os outros agentes tradicionais de limpeza das mãos, utilizando mãos contaminadas como modelo experimental ${ }^{22}$. Este resultado está de acordo com os estudos efetuados por outros pesquisadores, fora do Brasil ${ }^{24 / 27}$, e é considerado um efeito satisfatório.

O Biogel ${ }^{\circledR}$ apresentou atividade bactericida frente $P$. aeruginosa, E. cloacae, $R$. pickettii, $A$. baumannii, S. aureus, S. saprophyticus. Estes resultados assemelham-se ao encontrado na literatura como referido, e reafirmam a já bem estabelecida atividade antimicrobiana dos álcoois sobre cocos grampositivos, enterobactérias, bacilos gram- negativos não fermentadores da glicose, micobactérias (ex. Mycobacterium tuberculosis), sobre alguns fungos e vírus lipofílicos, não possuindo atividade sobre esporos bacterianos e vírus hidrofílicos $7,10,11,19$.

$\mathrm{Na}$ segunda etapa da pesquisa não se evidenciou nenhum efeito adverso e o índice de infecção foi nulo, tanto com a utilização do álcool $70 \%$ quanto o Biogel ${ }^{\circledR}$, corroborando assim a favor da utilização deste último, permitindo a supressão da etapa da lavagem com água e sabão líquido na região da FAV. Estes resultados são animadores tanto aos pacientes que possuem dificuldades na lavagem do braço da FAV antes da sessão de hemodiálise, pela limitação física, pelas limitações ergonômicas e de segurança devido a idade avançada, quanto àqueles que demonstram resistência na lavagem do braço na região da FAV, anteriormente às punções.

\section{5- CONCLUSÃO}

Os resultados obtidos neste estudo referentes à eficácia do álcool líquido $70 \%$ comparativamente ao álcool gel e o poder bactericida do novo produto Biogel ${ }^{\circledR}$ permitiram concluir que é viável a utilização deste produto testado, suprimindo a lavagem da pele na região da FAV, o uso da pia, água, sabão, diminuindo os custos, efluentes líquidos, resíduos sólidos e energia, e obtendo um resultado eficiente, de $72,7 \%$ de culturas negativas devido a ação antimicrobiana na higienização da pele destes pacientes, bem como índice nulo de infecção nos mesmos.

Burg G, Portela O, Paraginski GL, Souza V, Silveira DD, Hörner R. Study of the effectiveness of a new product to the alcohol gel base utilized as an antiseptic in a nephrology service. Medicina (Ribeirão Preto) 2007; 40 (2): $236-42$.

ABSTRACT: The healthcare is always challenged by medical assistance related infections, which generate higher rates of morbidity and mortality as well as unnecessary costs. The ethyl alcohol has been recognized for its antimicrobial activity against most microorganisms that cause infections in the healthcare setting. The major disadvantage of alcohol for skin antisepsis is its drying effect. This study was performed at the Clínica Renal in Santa Maria, RS, with the objective of testing a new biogel product, alcohol gel, to evaluate its efficacy as a hospital antiseptic, eliminating the necessity of washing the arm of the arterial-venous fistula (AVF) of the patient submitted to hemodialysis. The methodology used was the "Randomized Clinical Trial" and was carried out in eleven patients submitted to hemodialysis in January and February 2005. The study included the culture of skin before and after the antiseptic proceedings, using alcohol $70 \%$ and the Bioge ${ }^{\circledR}$ product, and the evaluation of the bacteriostatic and bactericide of the Biogel against gram-negative and gram-positive bacteria. The results showed that the performance of both antiseptics methods was the same, presenting an antiseptic activity of $72.7 \%$ and giving the Biogel ${ }^{\circledR}$ bactericide activity against the tested microorganisms.

Keywords: Alcohols. Disinfection. Antisepsis. Hemodialysis. Hospital Infection. 


\section{REFERÊNCIAS}

1 - Santos AAM, Verotti MP, Sanmartin A, Mesiano ERAB. Importância do álcool no controle de infecções em serviços de saúde. Avaliável on line: http: www.anvisa.gov.br/ servicosaude/controle/controle_alcool.pdf. Acesso em 04/ 04/2006.

2 - Larson E. Hygiene of skin: when is clean too clean? Emerg Infect Dis 2001; 7 (2): 225-30.

3 - Balsamo AC, Silveira IR, Chiaratto, VC. Manual para prevenção das infecções Hospitalares. Hospital Universitário-Universidade de São Paulo - CCIH - São Paulo HU/USP, 2003.

4 - Kampf G, Kramer A. Epidemiologic background of hand hygiene and evaluation of the most important agents for scrubs and rubs. Clin Microbiol Rev 2004; 17(4): 863-93.

5 - Widmer AF. Replace hand washing with use of a waterless alcohol hand rub? Clin Infect Dis 2000; 31: 136-43.

6 - Santos AAM. Controle de Infecção: necessidade de novos conceitos. Prática Hospitalar 2003; 28, Avaliável on line: http: www.praticahospitalar.com.br/pratica\%2028/paginas/ materia\%208-28.html, em 06/03/2006.

7 - Murray PR, Rosenthal KS, Kobayashi GS, Pfaller, MA. Microbiologia médica. 4a ed. São Paulo: Editora Guanabara Koogan; 2004.

8 - Souza CL, Castro ARCM, Carvalho NCP, Stief ACF, Santana MR, Pereira EF. Estudo bacteriológico da microbiota das mãos em profissionais da saúde do núcleo do Hospital Universitário - UFMS. LAES\&HAES 2004; 148:74-84.

9 - Penna TCV. Métodos de desinfecção e esterilização. In: Mastroeni MF. Biossegurança aplicada a laboratórios de saúde. São Paulo: Editora Atheneu; 2004. p.133-65.

10 - Romão CMCA. Desinfecção e esterilização química. In: Teixeira $\mathrm{P}$, Valle $\mathrm{S}$. Biossegurança uma abordagem multidisciplinar. Rio de Janeiro: Editora Fiocruz; 1998. p. 133-62.

11 - Tortora G, Funke BR, Case CL. Microbiologia. 8a ed. Porto Alegre: Editora Artmed; 2005. p.196-200. Tipos de desinfetantes.

12 - Berns J. Infection with antimicrobial-resistant microorganisms in dialysis patients. Semin Dial 2003; 16 (1): 30-7.

13 - Gold HS. Moellering RC Jr. Antimicrobial drug resistance. N Engl J Med 1996; 335: 1445-53.

14 - Fridkin SK. Increasing prevalence of antimicrobial resistance in intensive care units. Crit Care Med 2001; 29:64-8.
15 - Tokars JI, Frank M, Alter MJ, Arduino MJ. National surveillance of dialysis-associated diseases in the United States, 2000. Semin Dial 2002; 15: 162-71.

16 - Centers for Disease Control: Recommendations for prevening transmission of infections among hemodialysis patients. MMWR Morb Mortal Wkly Rep; 2001, 50: 2-32.

17 - Pereira MG. Epidemiologia teoria e prática. Rio de Janeiro: Editora Guanabara Koogan; 1999.

18 - Murray PR, Baron E., Pfaller, MA, Tenover FC, Yolken RHM. Manual of clinical microbiology, 8a ed. Washington: American Society for Microbiology; 2003.

19 - Koneman EW, Allen SD, Janda WM, Schreckenberger MPC, Winn Jr. WC. Diagnóstico microbiológico - Texto e atlas colorido, 5a ed. São Paulo: MEDSI; 2001.

20 - Fernandes AT. Anti-sepsia das mãos: solução alcoólica versus álcool gel. Avaliável on line: http: www.ccih.med.br/ bibl-jun-2002-5.html. Acesso em 04/04/2006

21 - Andrade D, Santos LS, Oliveira BA, Beraldo CC. Álcoois: a produção do conhecimento com ênfase na sua atividade antimicrobiana. Medicina, Ribeirão Preto 2002; 35:7-13.

22 - Hernandes SED, Mello AC, Sant'Ana JJ, Soares VS, Cassiolato V, Garcia LB, Cardoso CL. The effectiveness of alcohol gel and other hand-cleansing agents against importatnt nosocomial Pathogens. Braz J Microbiol 2004;35:33-9.

23 - Pietsch H. Hand antiseptics: rubs versus scrubs, alcoholic solutions versus alcoholic gels. J Hosp Infect 2001; 48:33-6.

24 - Newman JL, Seitz JC. Intermittent use of an antimicrobial hand gel for reducing soap-induced irritation of health care personnel. Am J Infect Control 1990; 18: 194-200.

25 - Voss A, Widmer AF. No time for handwashing? Handwashing versus alcoholic rub: can we afford $100 \%$ compliance? Infect Control Hosp Epidemiol 1997; 18: 205-08.

26 - Zaragosa M, Sallés, M Gomez, J, Bayas JM, Trilha A. Handwashing with soa por alcoholic solutions? A randomizedclinical trial of its effectiveness. Am J Infect Control 1999; 27: 258-61.

27 - Daugirdas JT, Blake PG, Ing, TS. Handbook of dialysis. 3 ed. Philadelphia: Lippincott Williams \& Wilkins; 2003.

Recebido em 11/09/2006

Aprovado em 16/02/2007 